\title{
Cytosolic-free Calcium Increases to Greater Than 100 Micromolar in ATP-depleted Proximal Tubules
}

\author{
Joel M. Weinberg, ${ }^{\star}$ Julie A. Davis, ${ }^{\star}$ and Manjeri A. Venkatachalam ${ }^{\ddagger}$ \\ *Division of Nephrology, Department of Internal Medicine, University of Michigan and Veteran's Affairs Medical Center, Ann Arbor, \\ Michigan 48109; and $\doteqdot$ Departments of Pathology and Medicine, The University of Texas Health Science Center at San Antonio, San \\ Antonio, Texas 78284
}

\begin{abstract}
Previous studies have shown that cytosolic-free $\mathrm{Ca}^{2+}\left(\mathrm{Ca}_{\mathrm{f}}\right)$ increases to at least low micromolar concentrations during ATP depletion of isolated kidney proximal tubules. However, peak levels could not be determined precisely with the $\mathrm{Ca}^{2+}$-sensitive fluorophore, fura-2, because of its high affinity for $\mathrm{Ca}^{2+}$. Now, we have used two low affinity $\mathrm{Ca}^{2+}$ fluorophores, mag-fura-2 (furaptra) and fura-2FF, to quantitate the full magnitude of $\mathrm{Ca}_{\mathrm{f}}$ increase. Between 30 and $60 \mathrm{~min}$ after treatment with antimycin to deplete ATP in the presence of glycine to prevent lytic plasma membrane damage, $\mathrm{Ca}_{\mathrm{f}}$ measured with mag-fura- 2 exceeded $10 \mu \mathrm{M}$ in $91 \%$ of tubules studied and $68 \%$ had increases to greater than 100 $\mu M . \mathrm{Ca}_{\mathrm{f}}$ increases of similar magnitude that were dependent on influx of medium $\mathrm{Ca}^{2+}$ were also seen using the new low $\mathrm{Ca}^{2+}$ affinity, $\mathrm{Mg}^{2+}$-insensitive, fluorophore fura-2FF in tubules depleted of ATP by hypoxia, and these increases were reversed by reoxygenation. Total cell $\mathrm{Ca}^{2+}$ levels in antimycin-treated or hypoxic tubules did not change, suggesting that mitochondria were not buffering the increased $\mathrm{Ca}_{\mathrm{f}}$ during ATP depletion. Considered in the context of the high degree of structural preservation of glycine-treated tubule cells during ATP depletion and the commonly assumed $\mathrm{Ca}^{2+}$ requirements for phospholipid hydrolysis, actin disassembly, and $\mathrm{Ca}^{2+}$-mediated structural damage, the remarkable elevations of $\mathrm{Ca}_{\mathrm{f}}$ demonstrated here suggest an unexpected resistance to the deleterious effects of increased $\mathrm{Ca}_{\mathrm{f}}$ during energy deprivation in the presence of glycine. $(J$. Clin. Invest. 1997. 100:713-722.) Key words: hypoxia • glycine $\bullet$ mag-fura- $2 \cdot$ fura-2FF $\bullet$ kidney
\end{abstract}

\section{Introduction}

The mechanisms responsible for damage and disintegration of energy deprived cells have remained elusive despite much study. Deregulation of cellular $\mathrm{Ca}^{2+}$ homeostasis is among the processes potentially of importance. Multiple factors favor the increase of cytosolic-free $\mathrm{Ca}^{2+}\left(\mathrm{Ca}_{\mathrm{f}}\right)^{1}$ during injury, and increased $\mathrm{Ca}_{\mathrm{f}}$ is known to catalyze the breakdown of membranes

Address correspondence to Dr. Joel M. Weinberg, Nephrology Research, Room 1560, MSRB II, University of Michigan Medical Center, Ann Arbor, MI 48109-0676. Phone: 313-764-3157; FAX: 313-7630982. E-mail: wnberg@umich.edu

Received for publication 30 January 1997 and accepted in revised form 23 April 1997.

The Journal of Clinical Investigation

Volume 100, Number 3, August 1997, 713-722

http://www.jci.org and cytoskeletal structures by hydrolysis and disassembly (1-4). An understanding of these processes requires that abnormalities of $\mathrm{Ca}^{2+}$ homeostasis during cell injury be accurately characterized. The difficulties inherent in measuring $\mathrm{Ca}_{\mathrm{f}}$ are compounded by injury states and considerable controversy remains about the pathogenetic role of $\mathrm{Ca}_{\mathrm{f}}$ alterations (1-8).

Because of its structural complexity, fragility, and highly active transport systems, the proximal tubule has posed special challenges to assessment of $\mathrm{Ca}_{\mathrm{f}}$ and its role during injury. Damage to this nephron segment is of particular significance to kidney function during acute renal failure and the ability to readily isolate it provides opportunities to study injury processes of general interest in a well-preserved, highly differentiated epithelial cell in vitro. Recent observations have led to the refinement of methodology and an improved conceptual framework to address questions of mechanistic significance relevant to the role played by $\mathrm{Ca}_{\mathrm{f}}$ in proximal tubule damage. The recognition that simple restoration of glycine that is lost from cells during ATP depletion confers a high degree of resistance to lytic membrane damage has been particularly important in this regard and allows study of the full progression of prelethal injury and the biochemical events responsible for it in a fashion uncomplicated by development of nonspecific changes due to generalized cellular disruption (9-17). The 2-5 $\mathrm{mM}$ concentrations of glycine that confer protection when added to the medium of ATP-depleted, isolated tubules increase intracellular glycine to the same levels, which are at the low end of the range of renal cortex glycine concentrations measured in vivo in various species (11).

Glycine-replete tubules have been shown to be resistant to lytic membrane damage produced by extreme perturbations of $\mathrm{Ca}_{\mathrm{f}}$ induced by treatment with the ionophore, ionomycin, in combination with either the metabolic transport inhibitor, antimycin (13-16), or various uncouplers $(12,17,18)$. However, such tubules develop severe structural alterations associated with $\mathrm{Ca}^{2+}$-dependent phospholipid hydrolysis $(13,15,19)$ and actin disassembly $(16,20)$. The use of glycine has also led to the recognition that sustained increases of $\mathrm{Ca}_{\mathrm{f}}$ to at least low $\mu \mathrm{M}$ concentrations as measured by fura- 2 develop during ATP depletion produced by hypoxia (21-24), antimycin $(13,19)$, or uncouplers $(12,17)$ without ionophore. However, under these conditions, structural damage in glycine-protected cells is less $(10,13,16,25)$ and phospholipid hydrolysis (15) and actin cy-

1. Abbreviations used in this paper: $\mathrm{Ca}_{\mathrm{f}}$, cytosolic-free $\mathrm{Ca}^{2+}$; EDTA, ethylenediaminetetraacetate; EGTA, ethyl glycol-bis ( $\beta$-amino-ethylether); FCCP, carbonyl cyanide p-trifluoromethoxyphenylhydrazone; LDH, lactate dehydrogenase; 1799, 2,6-dihydroxy-1,1,1,7,7,7-hexafluoro-2,6-bis(trifluoromethyl)heptan-4-one[bis(hexafluoroacetonyl)acetone; Rmax, ratio measured during perfusion with ionomycin in $3.5 \mathrm{mM} \mathrm{Ca}{ }^{2+}$ solution; Rmin, ratio measured during perfusion with EGTA and ionomycin in $\mathrm{Ca}^{2+}$-free solution. 
toskeletal alterations (16) are largely $\mathrm{Ca}^{2+}$-independent, thus bringing into question the true magnitude and significance of the $\mathrm{Ca}_{\mathrm{f}}$ increases measured with the fluorophore.

To the extent that they have been defined thus far, critical $\mathrm{Ca}^{2+}$ mediated events in ionophore-treated, ATP-depleted tubules have required $\mathrm{Ca}^{2+}$ concentrations of $\geq 10 \mu \mathrm{M}(15,20)$. Because of its high affinity for $\mathrm{Ca}^{2+}$, fura-2 does not accurately estimate $\mathrm{Ca}_{\mathrm{f}}$ at concentrations exceeding $1 \mu \mathrm{M}$ (26). Mag-fura-2 (furaptra) was introduced as a fluorophore suitable for assessing intracellular free $\mathrm{Mg}^{2+}$, although it was recognized from the outset that the dye is also highly $\mathrm{Ca}^{2+}$ responsive (27). The affinity of mag-fura- 2 for $\mathrm{Ca}^{2+}$ is substantially greater than its affinity for $\mathrm{Mg}^{2+}$, but much less than the affinity of fura- 2 for $\mathrm{Ca}^{2+}$ (27-29). This property has allowed use of mag-fura-2 in a number of systems to quantify $\mathrm{Ca}_{\mathrm{f}}$ increases well into the $\mu \mathrm{M}$ range (28, 30-33). Mag-fura-2 has also been used under conditions of ATP depletion to assess release of $\mathrm{Mg}^{2+}$ associated with hydrolysis of MgATP (33-36). During studies originally designed to assess $\mathrm{Mg}^{2+}$, we noted that mag-fura-2 fluorescence changes in ATP-depleted, isolated proximal tubules reflected increases of $\mathrm{Ca}_{\mathrm{f}}$ to the $\mu \mathrm{M}$ range with little or no interference from concomitant alterations of $\mathrm{Mg}^{2+}$. In this report we have corroborated this observation and used the method to assess the full extent of $\mathrm{Ca}_{\mathrm{f}}$ increase in ATP-depleted proximal tubules. The results indicate that sustained increases of $\mathrm{Ca}_{\mathrm{f}}$ to values that exceed $100 \mu \mathrm{M}$ develop in the majority of tubules subjected to $>30$ min antimycin-induced ATP depletion in the presence of glycine without evidence for lytic plasma membrane damage as indicated by accelerated fluorophore leakage or failure of vital dye exclusion. Moreover, we demonstrate similar increases of $\mathrm{Ca}_{\mathrm{f}}$ in glycine-protected hypoxic tubules that reverse with reoxygenation using a newly available, alternative, low affinity $\mathrm{Ca}^{2+}$ fluorophore, fura-2FF. Prelethal increases of $\mathrm{Ca}_{\mathrm{f}}$ of this magnitude have never been recognized previously in any cell type. Considered in light of the information on $\mathrm{Ca}^{2+}$ dependence of phospholipid and cytoskeletal alterations $(13,15,16,20)$ and the remarkable retention of structural integrity of glycine-protected cells during ATP depletion $(10,13,20)$, these data suggest exclusion of some cellular compartments from the increases of $\mathrm{Ca}_{\mathrm{f}}$ and/or an unexpectedly high resistance to the deleterious effects of $\mathrm{Ca}^{2+}$ in glycineprotected, ATP-depleted cells.

\section{Methods}

Isolation of tubules. Proximal tubules were prepared from kidney cortex of female New Zealand white rabbits (1.5-2.0 kg; Oakwood Farms, Oakwood, MI) by collagenase digestion and centrifugation on self-forming Percoll gradients $(9,11,12)$. Final tubule pellets were resuspended at a concentration of 4-5 mg tubule protein per milliliter in ice-cold medium gassed with $95 \% \mathrm{O}_{2} / 5 \% \mathrm{CO}_{2}$. The medium contained (in mM) $105 \mathrm{NaCl}, 2.6 \mathrm{KCl}, 25 \mathrm{NaHCO}_{3}, 2.4 \mathrm{KH}_{2} \mathrm{PO}_{4}, 1.25$ $\mathrm{CaCl}_{2}, 1.2 \mathrm{MgCl}_{2}, 1.2 \mathrm{MgSO}_{4}$, and, for most studies, 2.5 probenecid to promote intracellular retention of the fluorophores $(12,14)$. This medium also included (in $\mathrm{mM}$ ) 5 glucose, 4.5 sodium lactate, 1 alanine, and 10 sodium butyrate (Solution A).

Loading of tubules with mag-fura-2/acetoxymethylester (AM). To load cells with mag-fura-2 (Molecular Probes, Inc., Eugene, OR) or fura-2FF (TeFlabs, Austin, Texas), $25 \mu \mathrm{l}$ of $1.0 \mathrm{mM}$ stock solutions of the acetoxymethylester forms in dimethyl sulfoxide were mixed vigorously into $500 \mu \mathrm{l}$ of medium without tubules and the mixture was then added to $4.5 \mathrm{ml}$ of the tubule suspension to produce a $5 \mu \mathrm{M}$ final concentration. The siliconized, $25 \mathrm{ml}$ Erlenmeyer flask containing these tubules was gassed with $95 \% \mathrm{O}_{2} / 5 \% \mathrm{CO}_{2}$, sealed, and shaken gently in a water bath at $25^{\circ} \mathrm{C}$ for $60 \mathrm{~min}$. The tubules were then pelleted by centrifugation at $30 \mathrm{~g}$, washed twice in ice-cold medium containing (in mM) $110 \mathrm{NaCl}, 3.5 \mathrm{KCl}, 1.0 \mathrm{KH}_{2} \mathrm{PO}_{4}, 1.25 \mathrm{CaCl}_{2}, 1.0$ $\mathrm{MgCl}_{2}$, and $25 \mathrm{Na}-\mathrm{Hepes}, \mathrm{pH} 7.2$, and then resuspended in this medium (Solution B). 500- $\mu$ l aliquots of this suspension were applied to $25 \mathrm{~mm}$ diameter \#1 1/2 glass coverslips (Nicholson Precision Instruments, Gaithersburg, MD) that had been precoated with polyD-lysine. The coverslips were kept in covered 35-mm culture dishes at $4^{\circ} \mathrm{C}$ for a minimum of $20 \mathrm{~min}$ to allow maximal settling and adherence of tubules before study.

Fluorescence measurements in superfused tubules. A coverslip with adherent tubules was mounted in a Dvorak-Stotler culture chamber (Nicholson Precision Instruments) and perfusion at $0.82 \mathrm{ml} / \mathrm{min}$ from a 50-ml syringe, using a Harvard Apparatus, Inc. (South Natick, MA) Model 975 pump, was started immediately with a solution similar to Solution A except that the alanine concentration was reduced to 0.3 $\mathrm{mM}$, the sodium butyrate concentration was reduced to $5 \mathrm{mM}, 2$ or 5 $\mathrm{mM}$ glycine was present, and the $\mathrm{Ca}^{2+}$ and $\mathrm{Mg}^{2+}$ concentrations were adjusted as indicated for specific experiments (Solution C). The microfluorometric measurements were made using a Nikon Diaphot inverted microscope and a SPEX Industries (Edison, New Jersey) CM-2 spectrofluorometer system with the DM 3000 computer and software. The chamber and microscope stage were kept at $37^{\circ} \mathrm{C}$ using an Air Stream Incubator (Nicholson Precision Instruments). The tubule was viewed using a CF FLUOR 100× Oil/Iris lens (Nikon, Garden City, $\mathrm{NY}$ ) and was illuminated alternately with 340- and 380-nm excitation signals for $0.33 \mathrm{~s}$ through $0.4 \mathrm{~mm}$ slits ahead of the chopper, an ND0.3 neutral density filter (Omega Optical, Brattleboro, VT), and a DM 400 dichroic mirror (Nikon). Emitted light was collected through the dichroic mirror and then transmitted via a 420BA filter in the microscope and a 500FS40 filter (SPEX Industries) in the photomultiplier assembly to the fluorometer photomultiplier.

Mounting the chamber on the microscope stage, locating and positioning a tubule using visible light from the microscope, and making final adjustments to perfusion syringes and experimental parameters on the computer generally required 5-7 min during which the coverslip was perfused with Solution $\mathrm{C}$ at $37^{\circ} \mathrm{C}$. An additional period of 10-15 min perfusion with Solution $\mathrm{C}$ was then recorded before experimental maneuvers were started.

Experimental agents were introduced by replacing the perfusion syringe with one containing a solution of the desired composition, i.e., $95 \% \mathrm{O}_{2} / 5 \% \mathrm{CO}_{2}$-gassed Solution $\mathrm{C}$ with ATP-depleting metabolic inhibitor and various $\mathrm{Ca}^{2+}$ concentrations or, for hypoxia studies, $95 \% \mathrm{~N}_{2} / 5 \% \mathrm{CO}_{2}$-gassed Solution C containing $1800 \mathrm{mU} / \mathrm{ml}$ of Oxyrase (Oxyrase Inc., Mansfield, Ohio) to maximize the degree of hypoxia (37). Reoxygenation after hypoxia was done with $95 \% \mathrm{O}_{2} / 5 \%$ $\mathrm{CO}_{2}$-gassed Solution $\mathrm{C}$ that was further supplemented with $4 \mathrm{mM}$ each of $\alpha$-ketoglutarate and aspartate (38) and $250 \mu \mathrm{M}$ MgATP (39) to promote rapid recovery of cell ATP. In some experiments, after ATP depletion or reoxygenation, tubules were superfused with $1 \mu \mathrm{M}$ antimycin plus $15 \mu \mathrm{M}$ ionomycin in 10,50 , or $100 \mu \mathrm{M} \mathrm{Ca}^{2+}$ medium (prepared using EGTA/ $\mathrm{Ca}^{2+}$-buffered solutions as in reference 20) to provide an additional internal calibration point for the response of each tubule at these $\mathrm{Ca}^{2+}$ levels spanning the response range of greatest interest. After the last desired experimental maneuver, tubules were subjected to a terminal calibration procedure consisting of perfusion with a nominally $\mathrm{Ca}^{2+}$ and/or $\mathrm{Mg}^{2+}$-free form of Solution $\mathrm{C}$ that also contained $2.5 \mathrm{mM}$ ethylene glycol-bis( $\beta$-amino-ethyl-ether) (EGTA) or $2.5 \mathrm{mM}$ ethylenediaminetetraacetate (EDTA) and 15 $\mu \mathrm{M}$ ionomycin or $15 \mu \mathrm{M}$ bromo-A23187 (Calbiochem Corp., La Jolla, CA), followed by Solution $\mathrm{C}$ supplemented with $\mathrm{Ca}^{2+}$ to 3.5 $\mathrm{mM}$ or $\mathrm{Mg}^{2+}$ to $20 \mathrm{mM}$ and $15 \mu \mathrm{M}$ ionomycin or $15 \mu \mathrm{M}$ 4-bromoA23187, then by Solution C containing $200 \mu \mathrm{M} \mathrm{MnCl}$. Each of the calibration solutions was continued until the response was stable. Glycine at 2 or $5 \mathrm{mM}$ concentrations was present in all experimental and calibration solutions. This completely prevents lytic membrane damage and the associated accelerated dye leakage under these ex- 
perimental conditions $(12,13,15)$. As we have observed previously for fura-2 (12), superfusion with $20 \mu \mathrm{M}$ digitonin rapidly decreased mag-fura- 2 and fura-2FF fluorescence by $>90 \%$ indicating predominant cytosolic localization of both fluorophores.

For quantitation of $\mathrm{Ca}_{\mathrm{f}}$, the values of the 340 and $380 \mathrm{~nm}$ signals at the end of the $\mathrm{MnCl}_{2}$ perfusion were subtracted to correct for autofluorescence and other $\mathrm{Ca}^{2+}$-independent fluorescence in the system (12). $\mathrm{Ca}_{\mathrm{f}}$ was calculated from the background-corrected 340/380 ratios using the equation:

$$
\left[\mathrm{Ca}^{2+}\right]_{\mathrm{f}}=\left(\mathrm{K}_{\mathrm{d}} \cdot \mathrm{S}_{\mathrm{f} 2} / \mathrm{S}_{\mathrm{b} 2}\right) \cdot(\mathrm{R}-\mathrm{Rmin}) /(\mathrm{Rmax}-\mathrm{R})
$$

where $R$ is the ratio at any point; $R \min$ is the ratio measured during perfusion with EGTA and ionomycin in $\mathrm{Ca}^{2+}$-free solution $\mathrm{C}$; Rmax is the ratio measured during perfusion with ionomycin in $3.5 \mathrm{mM}$ $\mathrm{Ca}^{2+}$ solution $\mathrm{C} ; \mathrm{Sf}_{2}$ is the absolute value of the corrected 380 signal at Rmin; $S b_{2}$ is the absolute value of the corrected 380 signal at Rmax. A $K_{\mathrm{d}}$ of $33 \mu \mathrm{M}$ for $\mathrm{Ca}^{2+}$ was measured as described in Results for intracellular mag-fura-2 and the $K_{\mathrm{d}}$ of fura-2FF was similarly measured to be $13 \mu \mathrm{M}$. These values were used in all calculations of $\mathrm{Ca}_{\mathrm{f}}$. No attempt was made to mathematically correct for fluorescence secondary to concomitant changes of $\left[\mathrm{Mg}^{2+}\right]$ in the mag-fura- 2 studies because such changes were either absent or small under the experimental conditions (see Results).

Measurement of total cell $\mathrm{Ca}^{2+}$ and lytic damage in suspended tubules. Flasks containing tubules in Solution A without probenecid were incubated at $37^{\circ} \mathrm{C}$ for $15 \mathrm{~min}$ in the metabolic shaker. Then, experimental additions were made, flasks were regassed with $95 \% \mathrm{O}_{2} /$ $5 \% \mathrm{CO}_{2}$ or, for hypoxia studies, $95 \% \mathrm{~N}_{2} / 5 \% \mathrm{CO}_{2}$, and were incubated for 15-60 min before sampling. Total cell $\mathrm{Ca}^{2+}$ was measured by atomic absorption spectroscopy in tubules separated from their medium by centrifugation through bromododecane (Aldrich Chemical Co., Milwaukee, WI) and was factored by cell protein measured by the Lowry method as described previously (9). Lactate dehydrogenase (LDH) was measured in the medium before and after the addition of $0.1 \%$ Triton X-100 (40).

Reagents. Reagents were obtained from Sigma Chemical Co. (St. Louis, MO) unless otherwise indicated. 2,6-dihydroxy-1,1,1,7,7,7hexafluoro-2,6-bis(trifluoromethyl)heptan-4-one[bis(hexafluoroacetonyl)acetone(1799), a nonfluorescent uncoupler of mitochondrial oxidative phosphorylation (41), was provided by Dr. Peter Heytler (DuPont, Wilmington, DE). 1799 or an alternative low fluorescence uncoupler, carbonyl cyanide p-trifluoromethoxyphenylhydrazone (FCCP), antimycin, and ionomycin were delivered from 1,000 $\times$ absolute ethanol stocks. Free $\mathrm{Ca}^{2+}$ levels in reduced $\mathrm{Ca}^{2+}$ experimental solutions were verified with the pentapotassium salts of either fura-2 (solutions with $<1 \mu \mathrm{M}$ free $\mathrm{Ca}^{2+}$ ) or calcium orange-5N (solutions with $>3-5 \mu \mathrm{M} \mathrm{Ca}^{2+}$ ) as most appropriate (20).

Statistics. Data from multigroup experiments were analyzed statistically by analysis of variance for repeated measure designs. Individual group comparisons were then made using the Neuman-Keuls test for multiple comparisons (SigmaStat; Jandel Scientific, San Rafael, CA). Two group studies were assessed using paired or unpaired $t$ tests as appropriate. $P<0.05$ was considered to be statistically significant.

\section{Results}

Fig. 1 illustrates representative tracings from the initial experiments assessing fluorescence of mag-fura-2-loaded tubules subjected to ATP depletion induced by either the electron transport inhibitor, antimycin, or the nonfluorescent uncoupler, 1799, in the presence of glycine. Some tubules such as those shown in $A$ and $B$ developed small increases of the $340 / 380$ ratio that were then returned to below the baseline by treatment with A23187 and EDTA in Ca, Mg-free medium. Further superfusion with $20 \mathrm{mM} \mathrm{Mg}^{2+}$ in Ca-free medium in
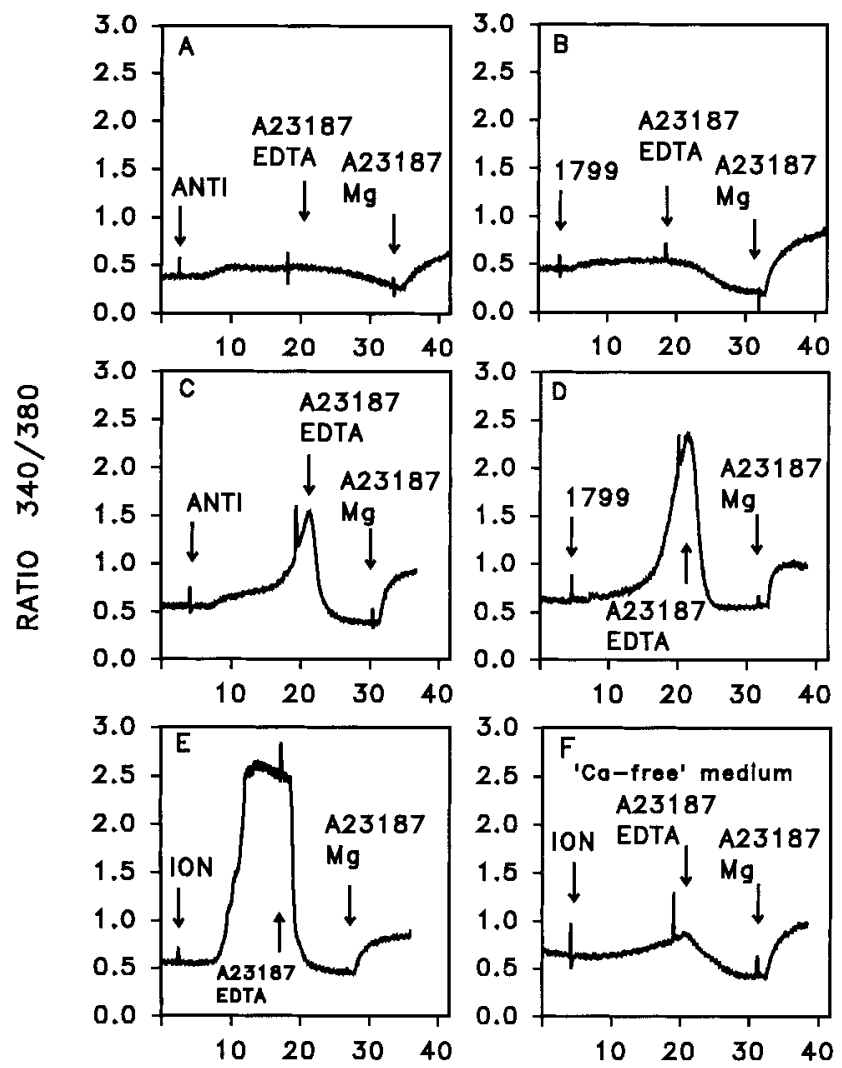

MINUTES OF PERFUSION

Figure 1. Initial studies of fluorescence changes in mag-fura-loaded tubules during ATP depletion conditions. Tubules were superfused for a baseline period in Solution C containing $1.25 \mathrm{mM} \mathrm{Ca}^{2+}$ and 2.4 $\mathrm{mM} \mathrm{Mg}{ }^{2+}$ with $2 \mathrm{mM}$ glycine followed by introduction in the same medium of either $1 \mu \mathrm{M}$ antimycin $(A N T I)(A$ and $C), 20 \mu \mathrm{M} 1799(B$ and $D), 15 \mu \mathrm{M}$ ionomycin $(I O N)(E)$ or $15 \mu \mathrm{M}$ ionomycin in Ca-free medium $(F)$. After 15 min with the experimental agent, perfusion was switched to $\mathrm{Ca}, \mathrm{Mg}$-free medium containing $2.5 \mathrm{mM}$ EDTA and 15 $\mu \mathrm{M}$ 4-bromo-A23187, which was followed by Ca-free medium supplemented with $20 \mathrm{mM} \mathrm{Mg}^{2+}$ and $15 \mu \mathrm{M}$ 4-bromo-A23187. A final perfusion with $\mathrm{Ca}, \mathrm{Mg}$-free medium containing $200 \mu \mathrm{M} \mathrm{MnCl}_{2}$ to quench mag-fura fluorescence for determination of background autofluorescence is not shown on the tracings. Values given are the ratios of the signals measured during alternate excitation at 340 and $380 \mathrm{~nm}$.

the continued presence of A23187 then produced a moderate increase of the fluorescence ratio. Other tubules, however, such as those shown in $C$ and $D$, developed large increases of the fluorescence ratio toward the end of the predefined period of treatment with the ATP-depleting agent. The increases substantially exceeded the values measured in the presence of 20 $\mathrm{mM} \mathrm{Mg}^{2+}$ and A23187. Because the timing of these changes in fluorescence was similar to those seen with the $\mathrm{Ca}^{2+}$ indicator, fura-2 (12), and, in view of the reported sensitivity of magfura-2 to $\mathrm{Ca}^{2+}(27,28,30-33)$, we then tested the effect of introducing ionomycin during the initial period of superfusion with regular medium containing $\mathrm{Ca}^{2+}$ and $\mathrm{Mg}^{2+}$. A large increase of fluorescence was seen $(E)$ and this increase was blocked if $\mathrm{Ca}^{2+}$ was removed from the medium despite continued superfusion with $\mathrm{Mg}^{2+}$. Consistent with the presence of 


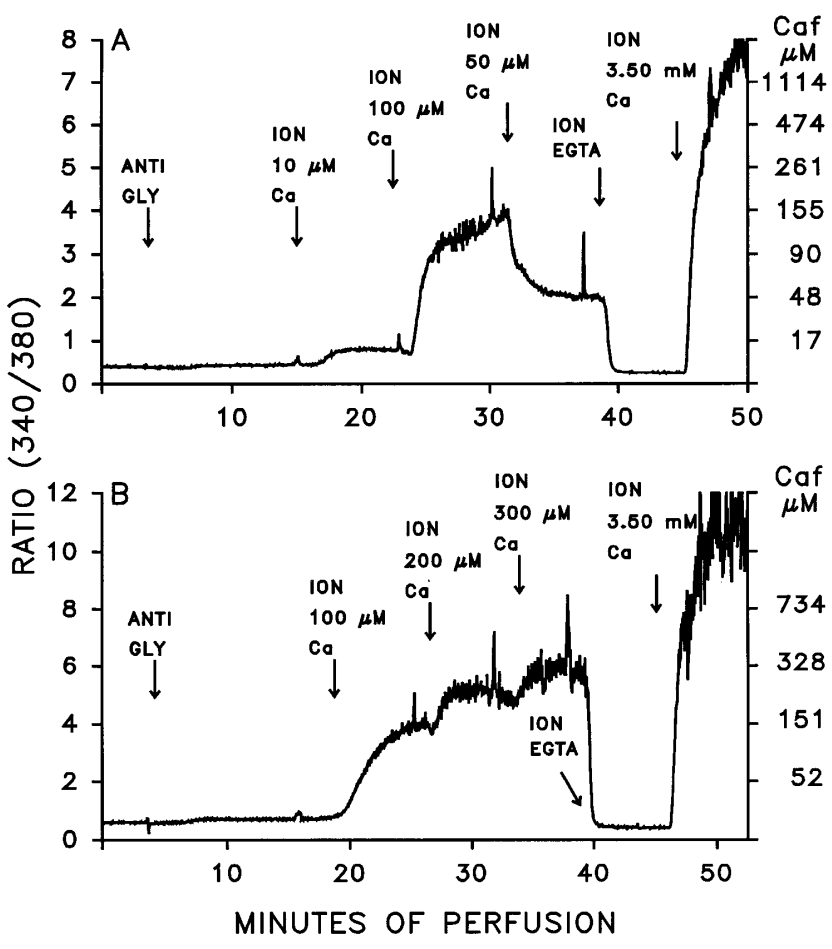

Figure 2. Fluorescence changes in antimycin + ionomycin-permeabilized, mag-fura-2-loaded tubules in media with various defined micromolar $\mathrm{Ca}^{2+}$ levels. Tubules were superfused with $\mathrm{Ca}, \mathrm{Mg}$-free Solution $\mathrm{C}$ for a baseline period followed by introduction of $1 \mu \mathrm{M}$ antimycin $(A N T I)+2 \mathrm{mM}$ glycine, followed by successive exposures to $\mathrm{Mg}$-free Solution C containing $15 \mu \mathrm{M}$ ionomycin (ION) in the continued presence of antimycin + glycine and the indicated $\mathrm{Ca}^{2+}$ concentrations. At the end of the experimental period, a calibration procedure consisting of superfusion with $\mathrm{Ca}, \mathrm{Mg}$-free Solution $\mathrm{C}$ containing $2.5 \mathrm{mM}$ EGTA, followed by superfusion with $15 \mu \mathrm{M}$ ionomycin in $\mathrm{Mg}$-solution C with $3.50 \mathrm{mM} \mathrm{Ca}{ }^{2+}$, then $200 \mu \mathrm{M} \mathrm{MnCl}_{2}$ (not shown) was done. All calibration solutions contained $5 \mathrm{mM}$ glycine. The left axis shows the 340/380 ratios, the right axis shows the calculated $\mathrm{Ca}_{\mathrm{f}}$ in micromolar using a $K_{\mathrm{d}}$ of $33 \mu \mathrm{M}$. (A) Experiment with 10, 50, and $100 \mu \mathrm{M} \mathrm{Ca}^{2+}$ medium. (B) Experiment with 100,200 , and $300 \mu \mathrm{M}$ $\mathrm{Ca}^{2+}$ medium. Studies are representative of $n=16$.

glycine, lytic membrane damage, which is recognizable in the superfusion system by rapid parallel decreases in both the 340 and $380 \mathrm{~nm}$ signals resulting from accelerated dye leakage (12), did not develop in any of these experiments or the subsequent fluorescence work.

Based on observations such as those shown in Fig. 1, further studies were done in $\mathrm{Mg}^{2+}$-free medium at various levels of $\mathrm{Ca}^{2+}$ to better define the $\mathrm{Ca}^{2+}$ sensitivity of mag-fura- 2 under our experimental conditions. Mag-fura-2-loaded tubules were initially treated with antimycin in the presence of glycine to inhibit ATP-dependent $\mathrm{Ca}^{2+}$ pumps that could, particularly at micromolar $\mathrm{Ca}^{2+}$ levels, oppose ionophore-induced equilibration of $\mathrm{Ca}^{2+}$ between the medium and the intracellular space (20), and then were exposed to ionomycin and varying medium $\mathrm{Ca}^{2+}$ levels. As shown in Fig. 2, $\mathrm{Ca}_{\mathrm{f}}$ alterations ranging from $10-20$ to $300-500 \mu \mathrm{M}$ were readily discriminated.

Figs. 3 and 4 show representative results of additional studies to further assess the degree to which the presence of $\mathrm{Mg}^{2+}$ in the medium affects measurement of fluorescence attribut- able to changes of intracellular $\mathrm{Ca}^{2+}$. For the experiments in Fig. 3, mag-fura-2-loaded tubules were treated with either ionomycin or antimycin + ionomycin in medium that was either free of added $\mathrm{Mg}^{2+}$ or contained $2.4 \mathrm{mM} \mathrm{Mg}^{2+}$ with either 100 $n \mathrm{M} \mathrm{Ca}^{2+}$, no added $\mathrm{Ca}^{2+}$ (Ca-free, which has a contaminating $\left[\mathrm{Ca}^{2+}\right]$ of $\left.10-15 \mu \mathrm{M}\right)$ or $1.25 \mathrm{mM} \mathrm{Ca}^{2+}$. In every case, the responses to ionomycin or antimycin + ionomycin reflected the available $\mathrm{Ca}^{2+}$ and were not affected by the $\mathrm{Mg}^{2+}$. In the studies shown in Fig. 4, tubules were initially superfused with $\mathrm{Ca}, \mathrm{Mg}$-free medium containing antimycin + ionomycin followed by introduction of either $1.25 \mathrm{mM} \mathrm{Ca}^{2+}$ (Fig. $4 \mathrm{~A}$ ), 170 $\mu \mathrm{M} \mathrm{Ca}^{2+}$ then $2.4 \mathrm{mM} \mathrm{Mg}^{2+}$ (Fig. 4 B), or $2.4 \mathrm{mM} \mathrm{Mg}^{2+}$ then $170 \mu \mathrm{M} \mathrm{Ca}^{2+}$ (Fig. 4 C). Introduction of $\mathrm{Mg}^{2+}$ during the experimental periods had little or no effect on fluorescence. Taken together with the observations in Figs. 1 and 2, these data indicate that fluorescence changes observed in mag-furaloaded tubules under conditions where $\mathrm{Ca}_{\mathrm{f}}$ excursions in the micromolar range occur almost entirely reflect these changes in $\mathrm{Ca}_{\mathrm{f}}$ with little contribution from intracellular or extracellular $\mathrm{Mg}^{2+}$ irrespective of the presence of ATP depleting conditions and/or divalent cation ionophores.

The ATP depletion conditions of interest required observation for up to $60 \mathrm{~min}$ during the experimental period as well as time for the baseline control perfusion, recovery when it was studied, and the terminal calibration procedures. Also, just before the calibration procedure to obtain Rmin and Rmax, we interposed a period of perfusion with antimycin + ionomycin + glycine in 10,50 , or $100 \mu \mathrm{M} \mathrm{Ca}^{2+}$ medium to provide an additional point of comparison with the spontaneous changes of $\mathrm{Ca}_{\mathrm{f}}$ that developed during ATP depletion. To obtain information from more than a single tubule during these experiments, we performed studies in which repeated measurements were made on the same areas of 7-9 nearby tubules during the sequential phases of the experiment (Fig. 5). These data are shown as the raw 340/380 fluorescence ratios to better illustrate the behavior of the individual tubules in the fashion that the data were collected. For each tubule, represented by a unique symbol, there is a baseline measurement, several measurements during treatment with antimycin + glycine (Fig. 5, $B$ and $C$ ), or a corresponding period of time control observation (Fig. $5 A$ ), a measurement in the presence of antimycin + ionomycin + glycine in 10 or $100 \mu \mathrm{M} \mathrm{Ca}^{2+}$ medium, a measurement during determination of Rmin in the presence of ionomycin and EGTA-containing Ca-free medium, and, finally, Rmax in the presence of ionomycin in $3.5 \mathrm{mM} \mathrm{Ca}^{2+} \mathrm{me}-$ dium. $\left[\mathrm{Mg}^{2+}\right]$ in all solutions was $2.4 \mathrm{mM}$.

Fig. $5 A$ shows a stable baseline signal in the control until introduction of the $100 \mu \mathrm{M}$ Ca medium with antimycin + ionomycin + glycine. In contrast, as seen in Fig. 5, $B$ and $C$, the majority of tubules treated with antimycin + glycine developed increases of the fluorescence ratio beginning after $30 \mathrm{~min}$ of exposure. That these values exceeded $10-100 \mu \mathrm{M} \mathrm{Ca}^{2+}$ is shown by the decreases of the fluorescence ratios seen during the subsequent superfusion with ionomycin and 100 or $10 \mu \mathrm{M}$ $\mathrm{Ca}^{2+}$ medium. Calculations of $\mathrm{Ca}_{\mathrm{f}}$ in 46 tubules studied during six such experiments are summarized Fig. 6. In $91 \%$ of the tubules, $\mathrm{Ca}_{\mathrm{f}}$ reached a level greater than $10 \mu \mathrm{M}$. In $22 \%$ of the tubules, these increases were in the range 10-100 $\mu \mathrm{M}$, however, the other $68 \%$ had increases to greater than $100 \mu \mathrm{M}$. In $35 \%$ of the tubules, calculated $\mathrm{Ca}_{\mathrm{f}}$ exceeded $500 \mu \mathrm{M}$, although these values should be considered approximate because of their distance from the $K_{\mathrm{d}}$. Similar behavior was observed in 

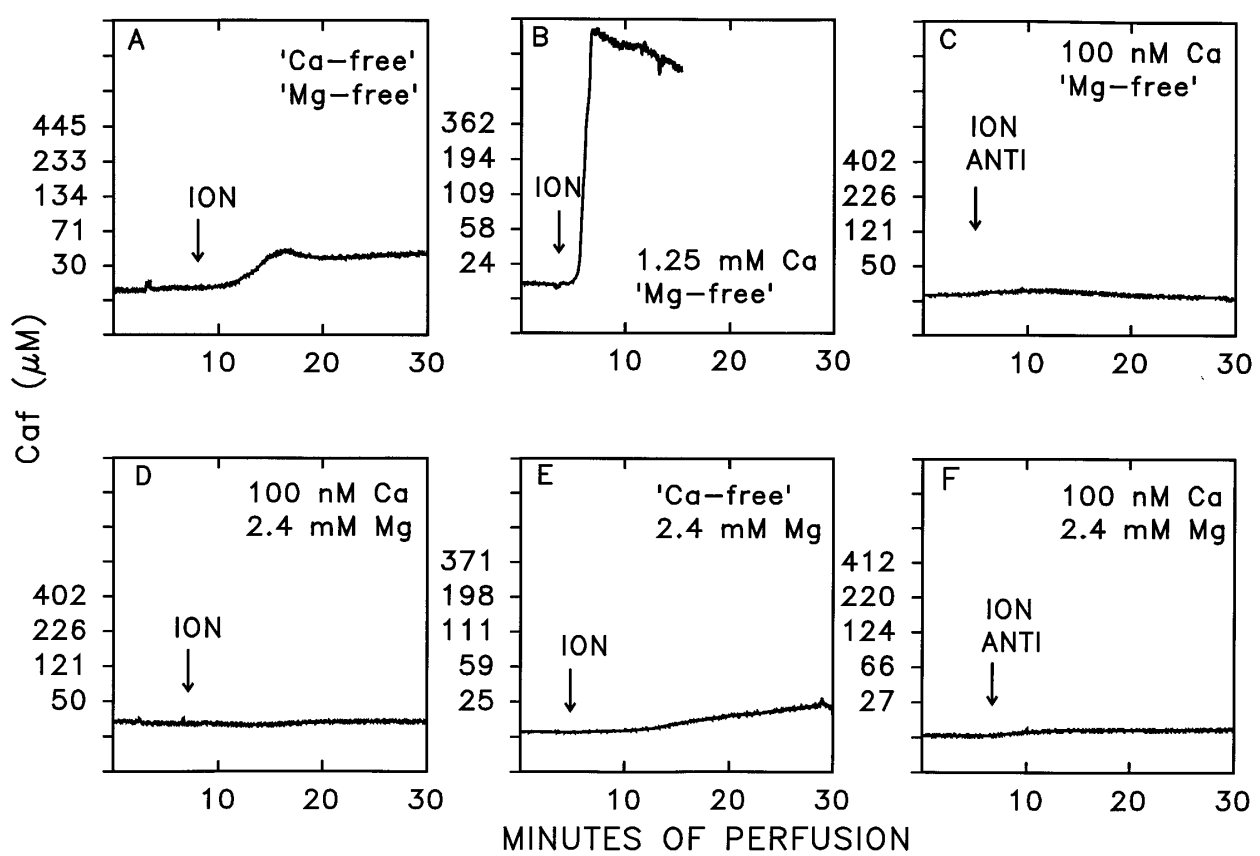

Figure 3. Effects of $\mathrm{Mg}^{2+}$ concentration on ionomycin-induced changes in the fluorescence signal at varying medium $\mathrm{Ca}^{2+}$ levels. Tubules were superfused in Solution C containing the indicated concentrations of $\mathrm{Ca}^{2+}$ and $\mathrm{Mg}^{2+}$ in the presence of $2 \mathrm{mM}$ glycine followed by introduction of $15 \mu \mathrm{M}$ ionomycin $(I O N)(A, B, D$, and $E)$ or ionomycin plus $1 \mu \mathrm{M}$ antimycin $(A N T I)(C$ and $F)$. Each of the experiments also had a terminal calibration procedure (not shown) as described in Fig. 2 that was used to obtain Rmin and Rmax for calculation of the $\mathrm{Ca}_{\mathrm{f}}$ values shown. Experiments are representative of results from $n=14$.
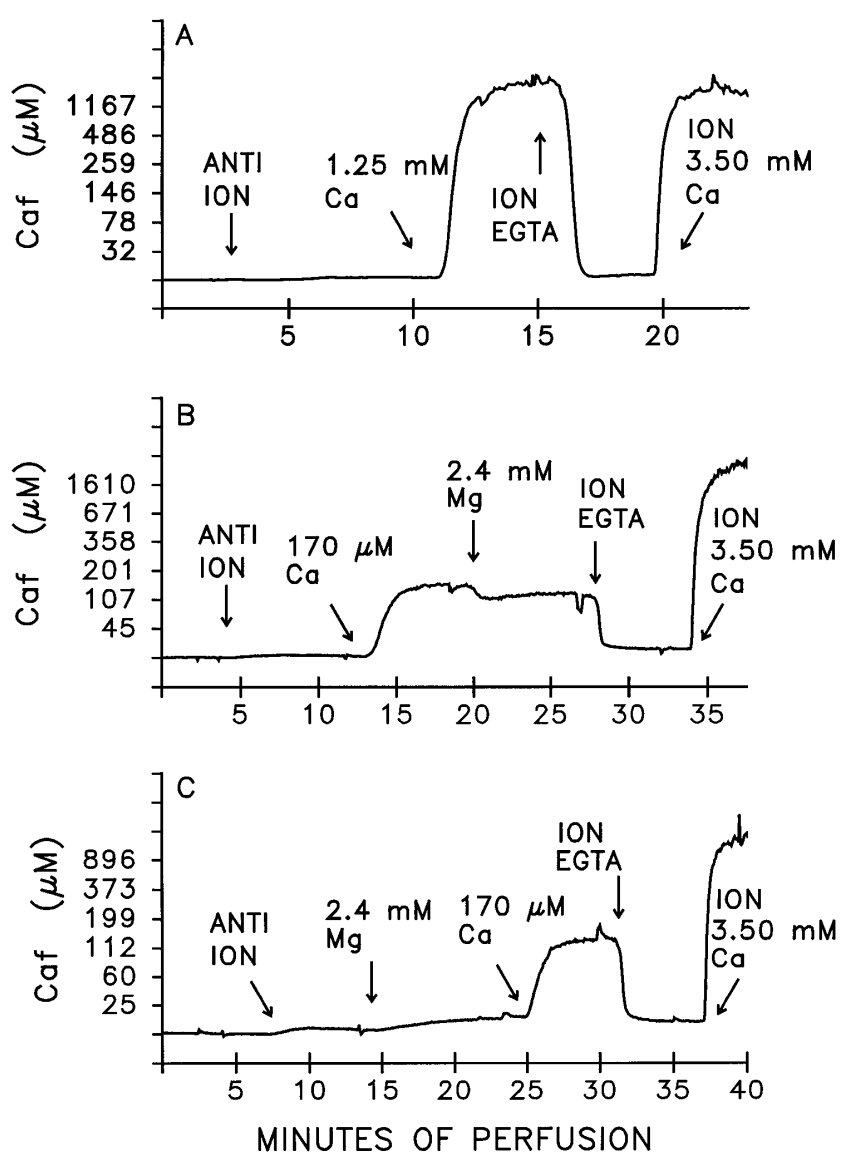

Figure 4. Effect of $\mathrm{Mg}^{2+}$ and $\mathrm{Ca}^{2+}$ concentration changes during superfusion on $\mathrm{Ca}_{\mathrm{f}}$ measurements. Glycine $(5 \mathrm{mM})$ was present during all phases of the experiment. Tubules were initially superfused in $\mathrm{Ca}, \mathrm{Mg}$-free Solution C supplemented with $100 \mu \mathrm{M}$ EGTA, followed by introduction of $1 \mu \mathrm{M}$ antimycin $(A N T I)$ plus $15 \mu \mathrm{M}$ ionomycin $(I O N)$ then, in the continued presence of antimycin plus ionomycin, six additional experiments in which ATP depletion was induced by the uncoupler, FCCP, instead of antimycin (not shown).

We have mainly used metabolic inhibitors, rather than hypoxia, for our studies of $\mathrm{Ca}_{\mathrm{f}}$ in ATP-depleted tubules because of difficulty in reproducibly maintaining $\mathrm{O}_{2}$ tension in the superfusion system at lower than $10 \mathrm{~mm} \mathrm{Hg}$ as required for truly hypoxic conditions (42). However, the unexpectedly large magnitude of the $\mathrm{Ca}_{\mathrm{f}}$ changes seen with antimycin made an assessment of hypoxia necessary to determine both whether increases of this degree occur during a more natural insult and whether they are reversible. To achieve the necessary degree of hypoxia, we included the oxygen consuming enzyme preparation, Oxyrase, in the medium (37) and all components of the perfusion system ahead of the chamber were kept under $\mathrm{N}_{2} / \mathrm{CO}_{2}$. Also, to further establish the general applicability of the estimates of $\mathrm{Ca}_{\mathrm{f}}$ made with mag-fura- 2 and their independence of $\mathrm{Mg}^{2+}$, we used an alternative, newly available, low $\mathrm{Ca}^{2+}$ affinity fluorophore, fura-2FF, that is not $\mathrm{Mg}$-sensitive for the hypoxia studies. Fig. $7 A$ illustrates the results of a representative study of this type using the multi-tubule protocol and including both a reoxygenation measurement and an extra internal calibration measurement with $50 \mu \mathrm{M} \mathrm{Ca}^{2+}$ medium in the presence of antimycin + ionomycin + glycine before the usual terminal calibration procedure. The fluorescence ratios increased during hypoxia in all tubules to values that reached or exceeded those measured subsequently in the same tubule

Solution $\mathrm{C}$ with either $1.25 \mathrm{mM} \mathrm{Ca}^{2+}(A), 170 \mu \mathrm{M} \mathrm{Ca}^{2+}$ then $2.4 \mathrm{mM}$ $\mathrm{Mg}^{2+}(B)$ or $2.4 \mathrm{mM} \mathrm{Mg}^{2+}$ then $170 \mu \mathrm{M} \mathrm{Ca}^{2+}(C)$. Each experiment ended with a terminal calibration procedure consisting of superfusion with ionomycin in $\mathrm{Ca}$-free Solution C containing $2.5 \mathrm{mM}$ EGTA and $2.4 \mathrm{mM} \mathrm{Mg}^{2+}$ followed by ionomycin in Solution C containing $3.5 \mathrm{mM}$ $\mathrm{Ca}^{2+}$ and $2.4 \mathrm{mM} \mathrm{Mg}^{2+}$, then $200 \mu \mathrm{M} \mathrm{MnCl}_{2}$ (not shown). Representative of $n=11$. 

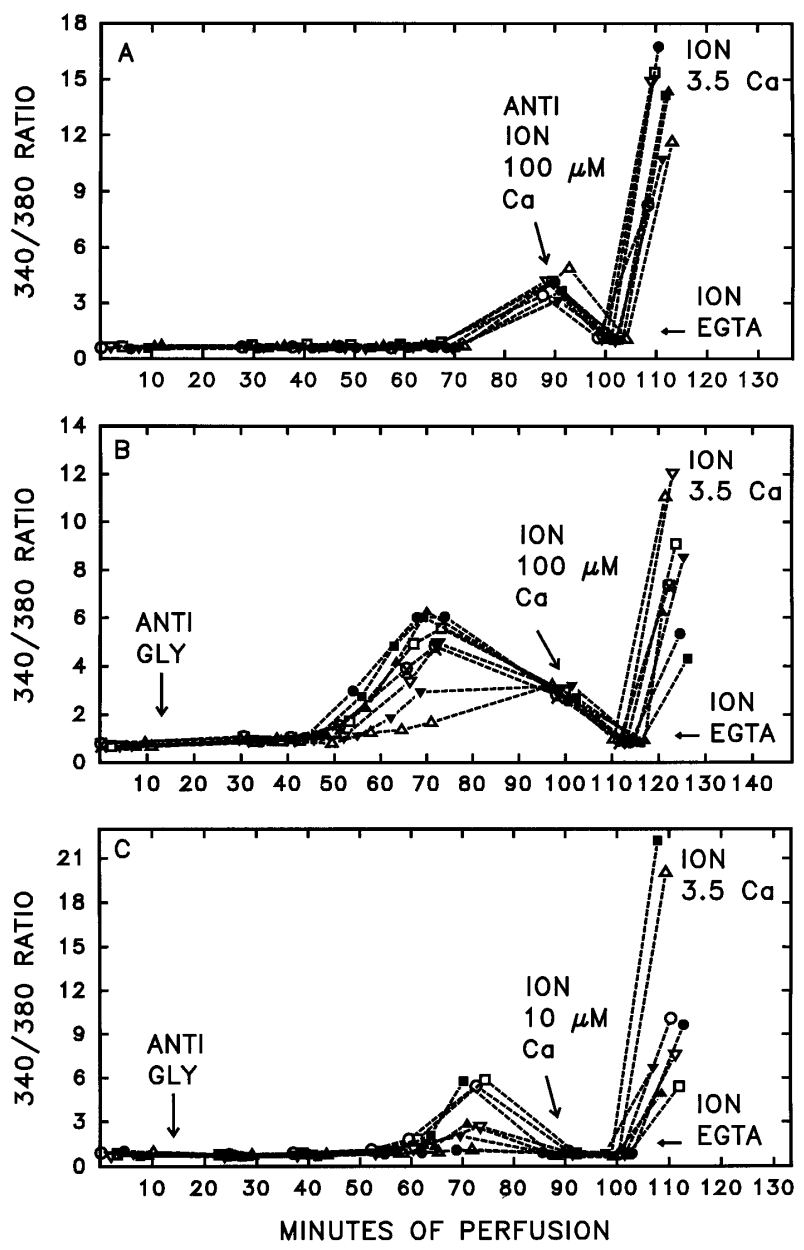

Figure 5. Effects of ATP depletion induced by antimycin in multiple tubule experiments. For each tubule, indicated by a unique symbol, the first time point is the reading at the end of the baseline period of perfusion under control oxygenated conditions. Tubules then received either no further additions $(A)$, or, at the points indicated by the arrows, $1 \mu \mathrm{M}$ antimycin $(A N T I)$ plus $5 \mathrm{mM}$ glycine $(G L Y)(B$ and $C)$. At the end of the experimental period, just before the calibration steps, an additional superfusion with $1 \mu \mathrm{M}$ antimycin plus $15 \mu \mathrm{M}$ ionomycin $(I O N)$ plus $5 \mathrm{mM}$ glycine in $100 \mu \mathrm{M}(A$ and $B)$ or $10 \mu \mathrm{M}$ (C) $\mathrm{Ca}^{2+}$ medium was included. The arrows for the ION, 10 or $100 \mu \mathrm{M}$ Ca labels indicate the points at which the responses to those conditions were measured. The last two points labeled are those used for measurement of Rmin in the presence of ionomycin $(I O N)$ and EGTA-containing Ca-free medium, and, finally, Rmax in the presence of ionomycin in $3.5 \mathrm{mM} \mathrm{Ca}^{2+}$ medium. $\mathrm{Mg}^{2+}(2.4 \mathrm{mM})$ was present in all experimental and calibration solutions. Data are shown as 340/380 ratios because the differences in Rmax between the individual tubules preclude a single common scale for the graph based on calculated $\mathrm{Ca}_{\mathrm{f}}$, other than a linear one which would not optimally show each tubule's behavior. The studies shown are representative of $n=6$ for antimycin-treated tubules and three controls. Six additional studies using the uncoupler, FCCP, instead of antimycin that did not include the full series of calibration steps also gave similar results.

during ionophore permeabilization in $50 \mu \mathrm{M} \mathrm{Ca}^{2+}$ medium and the hypoxia-induced increases of $\mathrm{Ca}_{\mathrm{f}}$ recovered during reoxygenation in 6 of the 7 tubules. Fig. $7 \mathrm{~B}$ illustrates the results of a similar experiment except that the medium $\mathrm{Ca}^{2+}$ was kept at $100 \mathrm{nM}$ during hypoxia. This prevented the increases of $\mathrm{Ca}_{\mathrm{f}}$

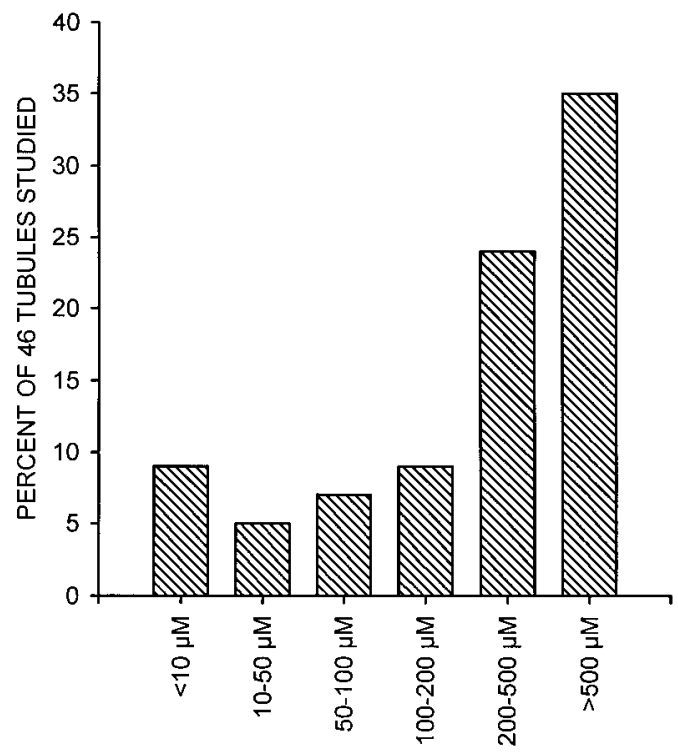

MAXIMAL [Caf] AFTER ANTIMYCIN+GLYCINE

Figure 6. Distribution of calculated $\mathrm{Ca}_{\mathrm{f}}$ in multitubule studies with antimycin + glycine. Data are from 46 tubules studied in six separate experiments such as those in Fig. 5, $B$ and $C$.

during hypoxia. The fluorescence change induced by $50 \mu \mathrm{M}$ $\mathrm{Ca}^{2+}$ in each tubule is illustrated by the subsequent perfusion with antimycin + ionomycin + glycine in $50 \mu \mathrm{M} \mathrm{Ca}^{2+}$ medium just before the terminal calibration steps.

The levels of $\mathrm{Ca}_{\mathrm{f}}$ measured during ATP depletion produced by antimycin or hypoxia are well in excess of those at which mitochondria are considered to buffer increased $\mathrm{Ca}_{\mathrm{f}}$ $(43,44)$. To assess whether a substantial amount of such buffering was occurring in the glycine-protected tubules, we measured total cell $\mathrm{Ca}^{2+}$, increases of which can reflect mitochondrial sequestration under injury conditions (6). Table I summarizes the measurements of total cell $\mathrm{Ca}^{2+}$ and of lytic membrane damage as measured by LDH release. During up to $60 \mathrm{~min}$ of either hypoxia or antimycin in the presence of glycine, there were no significant changes of total cell $\mathrm{Ca}^{2+}$ as compared to controls. As expected, glycine provided virtually complete protection against LDH release $(15,16)$.

\section{Discussion}

It is well-documented that $\mathrm{Ca}_{\mathrm{f}}$ is normally kept at $\sim 100 \mathrm{nM}$ or less, i.e., 1/10,000th the extracellular concentration, releasable intramitochondrial $\mathrm{Ca}^{2+}$ is minimal, an inositol trisphosphatesensitive $\mathrm{Ca}^{2+}$ pool sufficient to increase $\mathrm{Ca}_{\mathrm{f}}$ to high nanomolar levels is present in specialized forms of the endoplasmic reticulum, and considerable additional $\mathrm{Ca}^{2+}$ can be bound to cellular macromolecules (45-48). Observations consistent with these concepts have been made in kidney proximal tubules using fluorescent intracellular $\mathrm{Ca}^{2+}$ indicators $(12,49)$ and electron probe microanalysis (50-52). Increases of $\mathrm{Ca}_{\mathrm{f}}$ are opposed by combined actions of endoplasmic reticulum and plasma membrane Ca-ATPases and plasma membrane $\mathrm{Na}^{+} / \mathrm{Ca}^{2+}$ exchange $(45,46,48)$, although the latter process may not be expressed in proximal tubules (53). The mitochondrial $\mathrm{Ca}^{2+}$ transporter contributes at higher $\mathrm{Ca}_{\mathrm{f}}$ than the other mecha- 

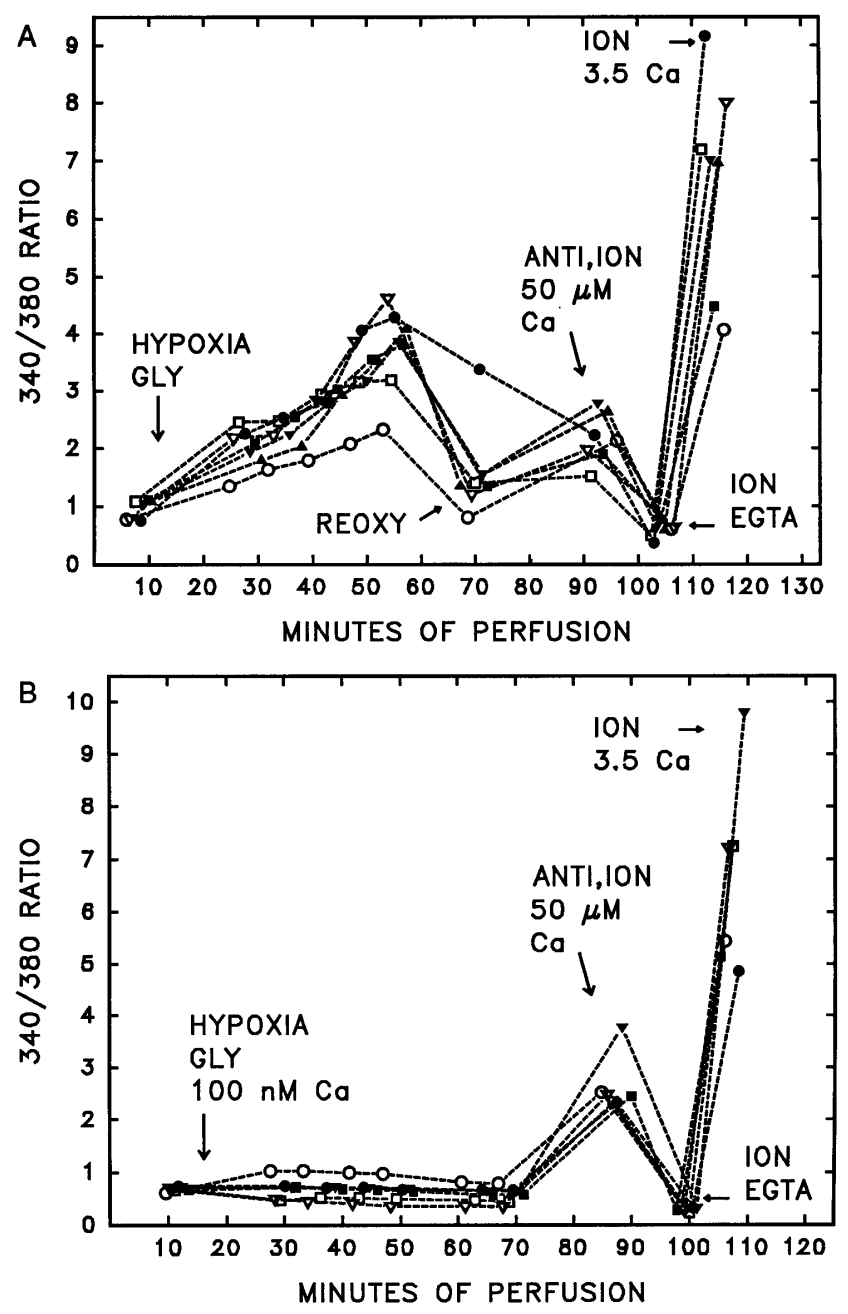

Figure 7. Representative multiple tubule studies illustrating effects of hypoxia in fura-2FF-loaded tubules. ( $A$ ) Hypoxia followed by reoxygenation in normal $1.25 \mathrm{mM} \mathrm{Ca}^{2+}$ medium. Results from each of seven tubules are represented by a unique symbol. The first point shown is at the end of the baseline period during superfusion under control, oxygenated conditions. Five $\mathrm{mM}$ glycine $(G L Y)$ was present throughout all experimental maneuvers and the calibration period. Hypoxia in the presence of Oxyrase to maximize the degree of oxygen deprivation was started at the indicated time followed by five readings. Tubules were then reoxygenated in medium that was further supplemented with $4 \mathrm{mM} \alpha$-ketoglutarate, $4 \mathrm{mM}$ aspartate, and $250 \mu \mathrm{M} \mathrm{MgATP}$ to promote metabolic recovery and an additional reading taken at the point marked REOXY. Then they were superfused with $1 \mu \mathrm{M}$ antimycin plus $15 \mu \mathrm{M}$ ionomycin $(A N T I, I O N)$ in $50 \mu \mathrm{M} \mathrm{Ca}^{2+}$ medium with a reading taken at the indicated point. Labeling of the terminal calibration maneuvers is the same as for Fig. 5 . Similar patterns of behavior were seen in all five experiments of this type that were done, each of which assessed 5-7 tubules. (B) Similar protocol and labeling as in $A$ except the superfusion medium $\mathrm{Ca}^{2+}$ concentration was $100 \mathrm{nM}$ and there was no reoxygenation period.

nisms $(43,44)$. Several factors during injury states potentially favor increases of $\mathrm{Ca}_{\mathrm{f}}$, i.e., opening of normal voltage dependent influx pathways by depolarization, development of pathologically increased plasma membrane permeability, diminished ATP to drive active plasma membrane extrusion and intracellular sequestration, and diminished mitochondrial elec-
Table I. Total Cell $\mathrm{Ca}^{2+}$ and LDH Release in Glycine-protected, ATP-depleted Tubules

\begin{tabular}{lcccccc}
\hline & \multicolumn{2}{c}{$\mathrm{Ca}^{2+}(\mathrm{nmol} / \mathrm{mg}$ protein $)$} & & \multicolumn{2}{c}{$\mathrm{LDH}$ (percentage free) } \\
\cline { 3 - 4 } & & $\begin{array}{c}\text { Time } \\
\text { control }\end{array}$ & Experimental & & $\begin{array}{c}\text { Time } \\
\text { control }\end{array}$ & Experimental \\
\hline 60' Hypoxia & 5 & $15.6 \pm 0.4$ & $12.5 \pm 0.8$ & & $10.5 \pm 1.1$ & $13.3 \pm 1.2$ \\
60' Antimycin & 5 & & $12.6 \pm 0.5$ & & $14.4 \pm 0.8$ \\
30' Hypoxia & 3 & $15.2 \pm 1.2$ & $18.0 \pm 2.4$ & & N.D. & N.D. \\
15' Antimycin & 5 & $19.4 \pm 1.1$ & $18.5 \pm 1.5$ & & $12.8 \pm 0.6$ & $14.0 \pm 0.3$
\end{tabular}

Value are means \pm SEM for the indicated number $(n)$ of separate tubule preparations studied. 60' Hypoxia and $60^{\prime}$ Antimycin experiments had the same time control. Glycine concentrations were: $5 \mathrm{mM}$ for $60 \mathrm{~min}$ studies, $4 \mathrm{mM}$ for $30 \mathrm{~min}$ studies, and $2 \mathrm{mM}$ for $15 \mathrm{~min}$ studies. N.D., not done.

tron transport to generate ATP and directly promote mitochondrial uptake.

There have been multiple reports describing increases of tubule cell $\mathrm{Ca}_{\mathrm{f}}$ measured with fura- 2 in various ATP depletion models using both cultured cells $(35,36,54-58)$, and, more recently with improvements in methodology, in freshly isolated proximal tubules that retain the normal fully differentiated phenotype of the epithelium $(12,13,17,22-24)$. In the freshly isolated tubule studies, $\mathrm{Ca}_{\mathrm{f}}$ has been shown to increase before lytic plasma membrane damage as indicated by loss of ability to exclude vital dyes $(12,21)$ or accelerated leakage of the fluorophore $\mathrm{Ca}^{2+}$ indicator (12). This has been most clearly evident in the presence of glycine, which prevents lytic membrane damage without affecting increases of $\mathrm{Ca}_{\mathrm{f}}$ in either ATPdepleted $(12,13,17,21,23)$ or ionophore-treated cells $(12,13$, $15,17)$, thus creating conditions where $\mathrm{Ca}_{\mathrm{f}}$ remains elevated for relatively prolonged periods in cells that maintain an apparently intact, limiting plasma membrane. Moreover, the timing and progression of various events in the presence of glycine is probably more relevant to that occurring in vivo where intracellular glycine concentrations are high normally and during ischemia $(11,52,59)$ and are decreased, but still substantial, during reperfusion $(52,59)$. The major sustained increases of $\mathrm{Ca}_{\mathrm{f}}$ in all studies that have examined the issue have been dependent on the presence of extracellular $\mathrm{Ca}^{2+}(12,15,21,23,24)$ and, when followed for sufficient lengths of time, have reached at least low $\mu \mathrm{M}$ levels that cannot be accurately quantitated with fura-2 $(12,13,17,22)$. The observations with both magfura- 2 and fura-2FF in this study provides evidence that these increases of $\mathrm{Ca}_{\mathrm{f}}$ in a majority of tubule cells reach $100 \mu \mathrm{M}$ and higher during 30-60 min of ATP depletion in the presence of glycine. Increases of $\mathrm{Ca}_{\mathrm{f}}$ of this magnitude during ATP depletion states have not been recognized previously in any cell type before lytic membrane damage.

Reported $K_{\mathrm{d}} \mathrm{s}$ of mag-fura- 2 for $\mathrm{Ca}^{2+}$ have ranged from $17-$ $60 \mu \mathrm{M}$ under various measurement conditions $(29,31,32)$. Our value of $33 \mu \mathrm{M}$ using in situ calibration is in good agreement. The $1.5 \mathrm{mM} K_{\mathrm{d}}$ of mag-fura-2 for $\mathrm{Mg}^{2+}(27,29)$ makes it suitable for assessment of free intracellular $\mathrm{Mg}^{2+}$ so long as $\mathrm{Ca}^{2+}$ does not reach $\mu \mathrm{M}$ concentrations (28-30,33). This has been the case in previous reports using mag-fura- 2 during ATP depletion insults, which have employed cultured cell systems where $\mathrm{Ca}_{\mathrm{f}}$ did not exceed high nanomolar levels (34-36). In 
contrast, mag-fura- 2 has served as a useful indicator of the full magnitude of increased $\mathrm{Ca}_{\mathrm{f}}$ in several physiological settings in which changes of $\mathrm{Mg}^{2+}$ were minimal or absent, but $\mathrm{Ca}_{\mathrm{f}}$ increased well into the $\mu \mathrm{M}$ range $(28,30-32)$. Despite the potential for shifts of $\mathrm{Mg}^{2+}$ related to hydrolysis of $\mathrm{MgATP}$ or other consequences of ATP depletion under the injury conditions used in the present studies (34-36), the data indicate that the major changes of mag-fura- 2 fluorescence measured in the isolated tubules reflected the behavior of intracellular $\mathrm{Ca}^{2+}$. Manipulations of medium $\mathrm{Ca}^{2+}$ at $\mu \mathrm{M}$ levels in the presence of ionomycin resulted in large, consistent changes of intracellular mag-fura-2 fluorescence that yielded a $K_{\mathrm{d}}$ value in good agreement with that expected for the interaction between $\mathrm{Ca}^{2+}$ and mag-fura- 2 and were not influenced substantially by the concomitant presence of $\mathrm{Mg}^{2+}$. The large fraction of mag-fura-2 that was releasable by digitonin is consistent with a predominant cytosolic origin of the signal. Mag-fura- 2 can be compartmentalized at intracellular sites of $\mathrm{Ca}^{2+}$ sequestration, and signals from these digitonin-insensitive sites have been used to measure $\mathrm{Ca}^{2+}$ levels in them $(60,61)$. However, the strength of these responses is a function of ATP availability, reflecting their requirement for active uptake (60), which is opposite of the behavior observed in our studies. Although the calibration procedure and $K_{\mathrm{d}}$ used gave highly reproducible values when tested with the solutions of defined $\mu \mathrm{M} \mathrm{Ca}^{2+}$ levels on antimycin + ionomycin-treated tubules, our conclusions about the magnitude of the $\mathrm{Ca}_{\mathrm{f}}$ increases during ATP depletion do not depend solely on these calculations. The studies in Fig. 5 clearly show that subsequent perfusion with calcium ionophore in $100 \mu \mathrm{M} \mathrm{Ca}^{2+}$ medium decreases the fluorescence ratios in individual tubules from the higher values during previous treatment with antimycin alone. Moreover, these changes were seen long after the development of ATP depletion and in the presence of constant medium $\mathrm{Mg}^{2+}$. They can only be explained by increases of $\mathrm{Ca}_{\mathrm{f}}$ during the ATP-depleted state that approach and frequently exceed $100 \mu \mathrm{M}$. This conclusion is further supported by similar findings in the hypoxia studies that used a different, more natural ATP-depleting insult and an alternative low affinity $\mathrm{Ca}_{\mathrm{f}}$ indicator, fura-2FF. There is only one previously published study with this newly available fluorophore (61). We have estimated its $K_{\mathrm{d}}$ to be $13 \mu \mathrm{M}$ under our experimental conditions, which is less than the $35 \mu \mathrm{M}$ stated by the manufacturer and less than the $K_{\mathrm{d}}$ of mag-fura-2, but still very suitable for the work. The hypoxia studies also showed that the large increases of $\mathrm{Ca}_{\mathrm{f}}$ measured were not simply the result of a late equilibration with medium $\mathrm{Ca}^{2+}$ levels in cells that were about to develop lytic damage despite the presence of glycine, since the increases of $\mathrm{Ca}_{\mathrm{f}}$ were reversible in a majority of the tubules and lytic membrane damage did not occur even during the further substantial prolongation of the experiments necessary to incorporate both the reoxygenation measurement and the subsequent step in which the response to $50 \mu \mathrm{M} \mathrm{Ca}^{2+}$ in the presence of ionomycin was assessed.

The interpretation of our data is dependent on the effect of ionomycin to equilibrate intracellular and extracellular free $\mathrm{Ca}^{2+}$. There are numerous precedents in the literature for in situ calibration in both cytosol and intracellular compartments using ionomycin and other divalent cation ionophores with respect to both high affinity $\mathrm{Ca}^{2+}$-sensitive fluorophores as well as the low affinity compounds we have used in this manuscript $(26,60-63)$. That the conditions under which we used ionomycin in the present studies, i.e., a high concentration $(15 \mu \mathrm{M})$ in the presence of metabolic inhibition induced by concomitant antimycin or immediately antecedent hypoxia, lead to full equilibration with medium $\mathrm{Ca}^{2+}$ is shown by our ability for both fluorophores to obtain $K_{\mathrm{d}} \mathrm{s}$ using in situ calibration with ionomycin that approximate those measured with the fluorophores in simple salt solutions. If ionomycin (plus antimycin or prior hypoxia) was not fully equilibrating medium and intracellular $\mathrm{Ca}^{2+}$, the $K_{\mathrm{d}} \mathrm{s}$ measured by intracellular calibration would have been far lower than those measured in simple salt solutions. There are also multiple other observations in this manuscript and in our previous work using these systems for the past 10 years that allow us to safely conclude that equilibration has taken place: (a) The rates of change upon introduction of the ionomycin (plus antimycin or with antecedent hypoxia) are relatively rapid and then cleanly asymptote; $(b)$ the terminal calibration procedure used to measure Rmax includes a very high concentration of medium $\mathrm{Ca}^{2+}$, i.e., $3.5 \mathrm{mM}$; (c) as discussed below, in previously published work $(13,15$, $16,20)$ we have assessed multiple intracellular metabolic effects of increased free $\mathrm{Ca}^{2+}$ induced by ionomycin + antimycin including ultrastructure, phospholipase $\mathrm{C}$ activity, phospholipase $A_{2}$ activity, and actin polymerization, all of which show the expected sensitivity to increased $\mathrm{Ca}^{2+}$ in an incremental fashion as medium $\mathrm{Ca}^{2+}$ is increased from $10 \mu \mathrm{M}$ up to 1.25 $\mathrm{mM} ;(d)$ we have also shown (20) how ionomycin alone, even at $15 \mu \mathrm{M}$, is not sufficient to fully equilibrate intra- and extracellular $\mathrm{Ca}^{2+}$ because of the continued operation of ATPdependent pumps, but the combination of ionomycin and antimycin as used for the present studies, overcomes this problem.

The contribution of increased $\mathrm{Ca}_{\mathrm{f}}$ to injury during ATP depletion has remained incompletely defined despite much work. In the absence of glycine, prevention of increased $\mathrm{Ca}_{\mathrm{f}}$ by lowering extracellular $\mathrm{Ca}^{2+}(12-15,21,42)$ or the use of an intracellular $\mathrm{Ca}^{2+}$ chelator (21) has delayed cell killing in some studies $(14,21,42)$, but not others $(12,13,15)$. In those studies where effects of $\mathrm{Ca}^{2+}$ removal were seen they were partial and relatively transient $(14,21,42)$. This behavior may reflect counterbalancing beneficial and deleterious effects of the $\mathrm{Ca}^{2+}$ manipulations per se $(19,64)$. In the presence of glycine, cytoprotective actions of the amino acid are dominant, so that cell killing is strongly suppressed irrespective of the behavior of $\mathrm{Ca}_{\mathrm{f}}(12,13,15,16)$, however a variety of potentially important $\mathrm{Ca}^{2+}$-dependent prelethal events become amenable to analysis $(13,15,16,20)$.

Recently, we have characterized the $\mathrm{Ca}^{2+}$ dependence of phospholipid degradation and actin polymerization during ATP depletion-induced tubule cell injury. In tubules treated with antimycin and the $\mathrm{Ca}^{2+}$ ionophore, ionomycin, in the presence of glycine to maximally equilibrate $\mathrm{Ca}^{2+}$ across cellular compartments without lytic membrane damage, 2/3 of unsaturated fatty acid accumulation was $\mathrm{Ca}^{2+}$-independent and the $\mathrm{Ca}^{2+}$-dependent component became evident only when the $\mathrm{Ca}^{2+}$ concentration exceeded $10 \mu \mathrm{M}$. When tubules were treated in the presence of glycine with antimycin alone or subjected to hypoxia, no $\mathrm{Ca}^{2+}$-dependent component was evident (15). Measurements of actin depolymerization in tubules treated with antimycin + ionomycin + glycine indicated a threshold of $10 \mu \mathrm{M} \mathrm{Ca}^{2+}$ for initiation of actin depolymerization, which was accompanied by swelling of microvilli and disruption of their actin cores (20). However, in glycine-treated tubules subjected to antimycin alone, or hypoxia, similar microvillar alterations developed in a $\mathrm{Ca}^{2+}$-independent fashion 
without actin depolymerization $(16,20)$. The current studies indicate that the failure of these $\mathrm{Ca}^{2+}$-dependent effects to occur during the ATP depletion states is not due to insufficient increase of $\mathrm{Ca}_{\mathrm{f}}$. We have also shown that it is not attributable to any direct effect of glycine to suppress these $\mathrm{Ca}^{2+}$-dependent processes $(15,20)$. Taken together, these observations suggest that the $\mathrm{Ca}^{2+}$-dependent alterations in unesterified fatty acid accumulation and actin depolymerization occur predominantly in cellular compartments that are protected from the fluorophore-detectable increases of $\mathrm{Ca}_{\mathrm{f}}$ during ATP depletion. The apical microvilli and mitochondria are two such sites.

The apical microvilli contain the largest pool of F-actin in the proximal tubule cells (16) and their earliest $\mathrm{Ca}^{2+}$-dependent structural changes correlate closely with alterations of actin polymerization and polyphosphoinositide degradation (13, 16). In this regard, electron microprobe studies have shown increased total $\mathrm{Ca}^{2+}$ in the microvillar compartment as compared to the cytosol, which may represent a greater binding capacity that could buffer ATP depletion-induced increases of $\mathrm{Ca}_{\mathrm{f}}(50,51)$.

The mitochondrial phospholipase $\mathrm{A}_{2}$ that is activated prominently by mitochondrial $\mathrm{Ca}^{2+}$ transport and buffering during injury states has a $\mathrm{Ca}^{2+}$ requirement in the low micromolar range $(65,66)$, which is similar to the threshold $\mathrm{Ca}^{2+}$ level for the $\mathrm{Ca}^{2+}$-dependent increment of fatty acid accumulation in the antimycin + ionomycin-treated tubule cells (15). The absence of a $\mathrm{Ca}^{2+}$-dependent component of fatty acid accumulation during ATP depletion may, thus, reflect the lack of mitochondrial $\mathrm{Ca}^{2+}$ uptake. This possibility is supported by the measurements of total cell $\mathrm{Ca}^{2+}$ in the glycine-protected cells subjected to ATP depletion by hypoxia or antimycin alone, which did not show the increases that would be expected if the mitochondria were accumulating $\mathrm{Ca}^{2+}$ to buffer the increases of $\mathrm{Ca}_{\mathrm{f}}(6,67)$. The absence of mitochondrial $\mathrm{Ca}^{2+}$ accumulation is consistent with the nature of the insult. Mitochondrial $\mathrm{Ca}^{2+}$ accumulation can be driven by either electron transport or ATP hydrolysis $(6,46)$. The $\mathrm{Ca}_{\mathrm{f}}$ increases in the ATP depleted tubules occurred in a delayed fashion well after maximal ATP depletion, so ATP-driven uptake would not be possible and both the hypoxic conditions and antimycin profoundly suppress electron transport.

Notwithstanding the apparent absence of $\mathrm{Ca}^{2+}$-dependent events in microvilli and mitochondria, the levels of $\mathrm{Ca}_{\mathrm{f}}$ reached in the glycine-protected, ATP-depleted tubules are remarkable when considered in the context of the high degree of overall structural preservation and the cohesiveness and normal appearing texture of the cytoplasmic matrix seen in them $(10,13,16)$. The findings, however, are consistent with the retention of many structural features in glycine-protected cells even when they are subject to yet greater perturbations of $\mathrm{Ca}_{\mathrm{f}}$ resulting from treatment with metabolic inhibitor plus $\mathrm{Ca}^{2+}$ ionophore in $\mathrm{Ca}^{2+}$-replete media (13). The freshly isolated tubule system used in this study does not permit assessment of whether the ATP depleted tubules that have sustained such large increases of $\mathrm{Ca}_{\mathrm{f}}$ are truly viable over the long term. Recently, however, we have addressed this question using MDCK cells treated with mitochondrial uncoupler and ionomycin in the presence of glycine in media with $\mathrm{Ca}^{2+}$ concentrations ranging from $26 \mathrm{nM}$ to $1.25 \mathrm{mM}$ (68). Exposure to concentrations of $\mathrm{Ca}^{2+}$ as high as $100 \mu \mathrm{M}$ for $3 \mathrm{~h}$ was compatible with sustained recovery of metabolic and proliferative function when the cells were returned to normal growth medium. At
$\mathrm{Ca}^{2+}$ levels $>100 \mu \mathrm{M}$ and durations greater then $3 \mathrm{~h}$, DNA damage became limiting for long term viability. We do not yet know whether such DNA damage is associated with the increases of $\mathrm{Ca}_{\mathrm{f}}$ to $>100 \mu \mathrm{M}$ that occur in the freshly isolated tubules under ATP depletion conditions in the absence of ionophore. Taken together, however, the data in the present studies and the MDCK cell observations provide evidence for an extraordinary degree of resistance to the potentially disruptive effects of increased $\mathrm{Ca}_{\mathrm{f}}$ during ATP depletion states so long as glycine is available and suggest that further investigation of the modification of $\mathrm{Ca}^{2+}$-regulated metabolic events as a function of glycine availability during ATP depletion will provide additional insight into critical determinants of cellular survival and structural integrity.

\section{Acknowledgments}

We appreciate the technical assistance of Nancy F. Roeser and Magaly Abarzua.

These studies were supported by Veteran's Affairs Department Merit Review funds, National Institutes of Health grant DK-34275, and Office of Naval Research contract N00014-95-1-584 to J.M. Weinberg and DK-37139 and DK48147 to M.A. Venkatachalam.

\section{References}

1. Farber, J.L. 1982. Biology of disease: membrane injury and calcium homeostasis in the pathogenesis of coagulative necrosis. Lab. Invest. 47:114-123.

2. Nicotera, P., G. Bellomo, and S. Orrenius. 1990. The role of $\mathrm{Ca}^{2+}$ in cell killing. Chem. Res. Toxicol. 3:484-494.

3. Weinberg, J.M. 1991. The cell biology of ischemic renal injury. Kidney Int. 39:476-500.

4. Weinberg, J.M. 1993. The cellular basis of nephrotoxicity. In Diseases of the Kidney. R.W. Schrier and C.W. Gottschalk, editors. Little, Brown and Co., Boston. 1031-1097.

5. Thomas, C.E., and D.J. Reed. 1989. Current status of calcium in hepatocellular injury. Hepatology. 10:375-384.

6. Weinberg, J.M. 1984. Calcium as a mediator of renal tubule cell injury. Sem. Nephrol. 4:179-191.

7. Herman, B., G.J. Gores, A.-L. Nieminen, T. Kawanishi, A. Harman, and J.J. Lemasters. 1990. Calcium and $\mathrm{pH}$ in anoxic and toxic injury. CRC Crit. Rev. Toxicol. 21:127-148.

8. Cheung, J.Y., J.V. Bonventre, C.D. Malis, and A. Leaf. 1986. Calcium and ischemic injury. N. Engl. J. Med. 314:1670-1676.

9. Weinberg, J.M., J.A. Davis, M. Abarzua, and T. Rajan. 1987. Cytoprotective effects of glycine and glutathione against hypoxic injury to renal tubules. $J$. Clin. Invest. 80:1446-1454.

10. Weinberg, J.M., M.A. Venkatachalam, R. Garza-Quintero, N.F. Roeser, and J.A. Davis. 1990. Structural requirements for protection by small amino acids against hypoxic injury in kidney proximal tubules. FASEB J. 4:3347-3354.

11. Weinberg, J.M., I. Nissim, N.F. Roeser, J.A. Davis, S. Schultz, and I. Nissim. 1991. Relationships between intracellular amino acid levels and protection against injury to isolated proximal tubules. Am. J. Physiol. 260:410-419.

12. Weinberg, J.M., J.A. Davis, N.F. Roeser, and M.A. Venkatachalam. 1991. Role of increased cytosolic free calcium in the pathogenesis of rabbit proximal tubule cell injury and protection by glycine or acidosis. J. Clin. Invest. 87:581-590.

13. Garza-Quintero, R., J.M. Weinberg, J. Ortega-Lopez, J.A. Davis, and M.A. Venkatachalam. 1993. Conservation of structure in ATP depleted proximal tubules. Role of calcium, polyphosphoinositides and glycine. Am. J. Physiol. 265:F605-F623.

14. Weinberg, J.M., J.A. Davis, N.F. Roeser, and M.A. Venkatachalam. 1994. Role of intracellular pH during cytoprotection of proximal tubule cells by glycine or acidosis. J. Am. Soc. Nephrol. 5:1314-1323.

15. Weinberg, J.M., M.A. Venkatachalam, H. Goldberg, N.F. Roeser, and J.A. Davis. 1995. Modulation by Gly, Ca, and acidosis of injury-associated unesterified fatty acid accumulation in proximal tubule cells. Am. J. Physiol. 268: F110-F121.

16. Nurko, S., K. Sogabe, J.A. Davis, N.F. Roeser, M. Defrain, A. Chien, D. Hinshaw, B. Athey, W. Meixner, M.A. Venkatachalam, and J.M. Weinberg. 1996. Contribution of actin cytoskeletal alterations to ATP depletion and calcium-induced proximal tubule cell injury. Am. J. Physiol. 270:F39-F52.

17. Venkatachalam, M.A., and J.M. Weinberg. 1993. Structural effects of intracellular amino acids during ATP depletion. In Surviving Hypoxia. Mecha- 
nisms of Control and Adaptation. P.W. Hochachka, P.L. Lutz, T. Sick, M. Rosenthal, and G. van den Thillart, editors. CRC Press, Boca Raton, FL. 474493.

18. Weinberg, J.M., M.A. Venkatachalam, N.F. Roeser, J.A. Davis, J. Varani, and K.J. Johnson. 1991. Amino acid protection of cultured kidney tubule cells against calcium ionophore-induced lethal cell injury. Lab. Invest. 65:671678.

19. Venkatachalam, M.A., J.M. Weinberg, Y. Patel, U. Hussong, and J.A. Davis. 1995. Effects of $\mathrm{Ca}^{++}$and glycine on lipid breakdown and death of ATPdepleted MDCK cells. Kidney Int. 48:118-128.

20. Sogabe, K., N.F. Roeser, J.A. Davis, S. Nurko, M.A. Venkatachalam, and J.M. Weinberg. 1996. Calcium dependence of integrity of the actin cytoskeleton of proximal tubule cell microvilli. Am. J. Physiol. 271:F292-F303.

21. Kribben, A., E.D. Wieder, J.F. Wetzels, L. Yu, P.E. Gengaro, T.J. Burke, and R.W. Schrier. 1994. Evidence for role of cytosolic free calcium in hypoxia-induced proximal tubule injury. J. Clin. Invest. 93:1922-1929.

22. Wieder, E.D., M.M. Yaqoob, C.L. Edelstein, T.D. Curren, P.E. Gengaro, R.A. Nemenoff, and R.W. Schrier. 1995. Time course of glycine cytoprotection in hypoxic proximal tubules. Proc. XIIIth Int. Congr. Nephrol. 166(Abstr.)

23. Rose, U.M., R.J. Bindels, J.W. Jansen, and C.H. Van Os. 1994. Effects of $\mathrm{Ca}^{2+}$ channel blockers, low $\mathrm{Ca}^{2+}$ medium and glycine on cell $\mathrm{Ca}^{2+}$ and injury in anoxic rabbit proximal tubules. Kidney Int. 46:223-229.

24. Barac-Nieto, M., R. Rozental, A. Constantinescu, D.C. Spray, and A. Spitzer. 1994. Mechanism of anoxia-induced increases in $\left[\mathrm{Ca}^{2+}\right] \mathrm{i}$ and cell injury in rabbit renal proximal tubules. J. Am. Soc. Nephrol. 5:892(Abstr.)

25. Weinberg, J.M., J.A. Davis, M. Abarzua, and T. Kiani. 1990. Glycinedependent protection of proximal tubules against lethal cell injury due to inhibitors of mitochondrial ATP production. Am. J. Physiol. 258:C1127-C1140.

26. Cobbold, P.H., and T.J. Rink. 1987. Fluorescence and bioluminescence measurement of cytoplasmic free calcium. Biochem. J. 248:313-328.

27. Raju, B., E. Murphy, L.A. Levy, R.D. Hall, and R.E. London. 1989. A fluorescent indicator for measuring cytosolic free magnesium. Am. J. Physiol. 256:C540-C548

28. Konishi, M., S. Hollingworth, A.B. Harkins, and S.M. Baylor. 1991. Myoplasmic calcium transients in intact frog skeletal muscle fibers monitored with the fluorescent indicator furaptra. J. Gen. Physiol. 97:271-301.

29. Murphy, E. 1993. Measurement of intracellular ionized magnesium. Miner. Electrolyte Metab. 19:250-258.

30. Hurley, T.W., M.P. Ryan, and R.W. Brinck. 1992. Changes of cytosolic $\mathrm{Ca}^{2+}$ interfere with measurements of cytosolic $\mathrm{Mg}^{2+}$ using mag-fura-2. Am. J. Physiol. 263:C300-C307.

31. Konishi, M., and J.R. Berlin. 1993. Ca transients in cardiac myocytes measured with a low affinity fluorescent indicator, furaptra. Biophys. J. 64: 1331-1343.

32. Ukhanov, K.Y., T.M. Flores, H.S. Hsiao, P. Mohapatra, C.H. Pitts, and R. Payne. 1995. Measurement of cytosolic $\mathrm{Ca}^{2+}$ concentration in Limulus ventral photoreceptors using fluorescent dyes. J. Gen. Physiol. 105:95-116.

33. Koss, K.L., R.W. Putnam, and R.D. Grubbs. 1993. $\mathrm{Mg}^{2+}$ buffering in cultured chick ventricular myocytes: quantitation and modulation by $\mathrm{Ca}^{2+}$. $\mathrm{Am}$. J. Physiol. 264:C1259-C1269.

34. Harman, A.W., A.-L. Nieminen, J.J. Lemasters, and B. Herman. 1990. Cytosolic free magnesium, ATP, and blebbing during chemical hypoxia in cultured rat hepatocytes. Biochem. Biophys. Res. Commun. 170:477-483.

35. Li, H., D. Long, C. Krieger, and G.A. Quamme. 1993. Intracellular $\mathrm{Mg}^{2+}$ concentrations following metabolic inhibition in opossum kidney cells. Biochim. Biophys. Acta. 1181:307-315.

36. Li, H., D. Long, and G.A. Quamme. 1993. Effect of chemical hypoxia on intracellular ATP and cytosolic $\mathrm{Mg}^{2+}$ levels. J. Lab. Clin. Med. 122:260-272.

37. Joseph, J.K., D. Bunnachak, T.J. Burke, and R.W. Schrier. 1990. A novel method of inducing and assuring total anoxia during in vitro studies of $\mathrm{O}_{2}$ deprivation injury. J. Am. Soc. Nephrol. 1:837-840.

38. Garza-Quintero, R., J. Ortega-Lopez, J.H. Stein, and M.A. Venkatachalam. 1990. Alanine protects rabbit proximal tubules against anoxic injury in vitro. Am. J. Physiol. 258:F1075-F1083.

39. Weinberg, J.M., J.A. Davis, A. Lawton, and M. Abarzua. 1988. Modulation of cell nucleotide levels of isolated kidney tubules. Am. J. Physiol. 254: F311-F322.

40. Weinberg, J.M., J.A. Davis, M. Abarzua, and T. Kiani. 1989. Relationship between cell ATP and glutathione content and protection by glycine against hypoxic proximal tubule cell injury. J. Lab. Clin. Med. 113:612-623.

41. Heytler, P.G. 1979. Uncouplers of oxidative phosphorylation. Methods. Enzymol. 55:462-472.

42. Takano, T., S.P. Soltoff, S. Murdaugh, and L.J. Mandel. 1985. Intracellu- lar respiratory dysfunction and cell injury in short-term anoxia of rabbit renal proximal tubules. J. Clin. Invest. 76:2377-2384.

43. Becker, G.L., G. Fiskum, and A.L. Lehninger. 1980. Regulation of free calcium by liver mitochondria and endoplasmic reticulum. J. Biol. Chem. 255: 9009-9012.

44. Nicchitta, C.V., and J.R. Williamson. 1984. Spermine. A regulator of mitochondrial calcium cycling. J. Biol. Chem. 259:12978-12983.

45. Williamson, J.R., and J.R. Monck. 1989. Hormone effects on cellular $\mathrm{Ca}^{2+}$ fluxes. Annu. Rev. Physiol. 51:107-124.

46. Carafoli, E. 1987. Intracellular calcium homeostasis. Annu. Rev. Biochem. 56:395-433.

47. Somlyo, A.P. 1985. Calcium content of mitochondria and endoplasmic reticulum in liver frozen rapidly in vivo. Nature (Lond.). 314:622-625.

48. Carafoli, E. 1991. Calcium pump of the plasma membrane. Physiol. Rev. 71:129-153.

49. Jacobs, W.R., M. Sgambati, G. Gomez, P. Vilaro, M. Higdon, P.D. Bell, and L.J. Mandel. 1991. Role of cytosolic Ca in renal tubule damage induced by anoxia. Am. J. Physiol. (Cell Physiol.). 260:C545-C554.

50. LeFurgey, A., A.J. Spencer, W.R. Jacobs, P. Ingram, and L.J. Mandel. 1991. Elemental microanalysis of organelles in proximal tubules. I. Alterations in transport and metabolism. J. Am. Soc. Nephrol. 1:1305-1320.

51. Spencer, A.J., A. LeFurgey, P. Ingram, and L.J. Mandel. 1991. Elemental microanalysis of organelles in proximal tubules. II. Effects of oxygen deprivation. J. Am. Soc. Nephrol. 1:1321-1333.

52. Beck, F.X., A. Ohno, A. Dorge, and K. Thurau. 1995. Ischemia-induced changes in cell element composition and osmolyte contents of outer medulla. Kidney Int. 48:449-457.

53. White, K.E., F.A. Gesek, T. Nesbitt, M.K. Drezner, and P.A. Friedman 1996. Molecular analysis of the $\mathrm{Ca}^{2+}$ efflux mechanisms in proximal tubule cells. J. Am. Soc. Nephrol. 7:1809(Abstr.)

54. Snowdowne, K.W., C.C. Freudenrich, and A.B. Borle. 1985. The effects of anoxia on cytosolic free calcium, calcium fluxes, and cellular ATP levels in cultured kidney cells. J. Biol. Chem. 260:11619-11626.

55. Goligorsky, M.S., D. Loftus, M. Huskey, and K.A. Hruska. 1987. Cytosolic $\left[\mathrm{Ca}^{2+}\right]$ in single proximal tubule cell (PTC) during anoxia and reoxygenation. Fed. Proc. 46:1327(Abstr.)

56. McCoy, C.E., A.M. Selvaggio, E.A. Alexander, and J.H. Schwartz. 1988 Adenosine triphosphate depletion induces a rise in cytosolic free calcium in canine renal epithelial cells. J. Clin. Invest. 82:1326-1332.

57. Phelps, P.C., M.W. Smith, and B.F. Trump. 1989. Cytosolic ionized calcium and bleb formation after acute cell injury of cultured rabbit renal tubule cells. Lab. Invest. 60:630-642.

58. Greene, E.L., and M.S. Paller. 1994. Calcium and free radicals in hypoxia/reoxygenation injury of renal epithelial cells. Am. J. Physiol. 266:F13F20.

59. Duran, M.-A., D. Spencer, M. Weise, N.O. Kronfol, R.F. Spencer, and D.E. Oken. 1990. Renal epithelial amino acid concentrations in mercury-induced and postischemic acute renal failure. Toxicol. Appl. Pharmacol. 105:183-194.

60. Hofer, A.M., and T.E. Machen. 1994. Direct measurement of free Ca in organelles of gastric epithelial cells. Am. J. Physiol. 267:G442-G451.

61. Golvina, V.A., and M.P. Blaustein. 1997. Spatially and functionally distinct $\mathrm{Ca}^{2+}$ stores in sarcoplasmic and endoplasmic reticulum. Science (Wash. DC). 275:1643-1648.

62. Lew, P.D., A. Monod, F.A. Waldvogel, B. Dewald, M. Baggiolini, and T. Pozzan. 1986. Quantitative analysis of the cytosolic free calcium dependency of exocytosis from three subcellular compartments in intact human neutrophils. J. Cell Biol. 102:2197-2204.

63. Williams, D.A., and F.S. Fay. 1990. Intracellular calibration of the fluorescent calcium indicator Fura-2. Cell Calcium. 11:75-83.

64. Davis, J.A., and J.M. Weinberg. 1988. Effects of glycine and GSH on toxic maneuvers altering tubule cell plasma membrane cation permeability. Clin. Res. 36:517A(Abstr.)

65. Nakamura, H., R.A. Nemenoff, J.H. Gronich, and J.V. Bonventre. 1991. Subcellular characteristics of phospholipase A2 activity in the rat kidney. Enhanced cytosolic, mitochondrial, and microsomal phospholipase A2 enzymatic activity after renal ischemia and reperfusion. J. Clin. Invest. 87:1810-1818.

66. Bjornstad, P. 1966. Phospholipase activity in rat liver mitochondria studied by the use of endogenous substrates. J. Lipid Res. 7:612-629.

67. Weinberg, J.M., J.A. Davis, and B. Trivedi. 1988. Calcium comparmentation in isolated renal tubules in suspension. Biochem. Med. Metab. Biol. 39: $234-245$.

68. Dong, Z., P. Saikumar, M. Venkatachalam, and J. Weinberg. 1996. Intracellular calcium levels that determine the survival of glycine protected ATP depleted cells. J. Am. Soc. Nephrol. 7:1823(Abstr.) 